\title{
Human resource management practices in Japan: Are they really changing?
}

\section{Meaghan Powell}

The 'typically Japanese' ways in which Japanese companies have long arranged their human resource practices are certainly changing. However, due to the entrenched nature of these practices and the significance of culture and tradition in Japan, these changes are slow and somewhat limited. ${ }^{1}$ This essay first explains the specific features of traditional Japanese human resource management practices. It then goes on to explore the economic environment of Japan and how this has informed the evolution of Japanese human resource management practices. The ways in which these traditional human resource practices are changing are then interrogated. It is clear that a tension exists in Japanese human resource practices between old and new: globalisation and economic factors have necessitated changes, however, traditional culture and ingrained mindsets, which inevitably inform human resource management practices, have resisted these changes. It is correct to say that Japanese human resource practices are really changing, however, these changes are limited in some respects.

1 Geert Hofstede, 'What About Japan?' Accessed 5 October 2016: geert-hofstede.com/ japan.html. 


\section{Traditional Japanese human resource practices}

Japanese culture is ancient and complex. ${ }^{2}$ Its rich traditions have manifested in a system of unique human resource management practices. Some core features of Japanese human resource management include lifetime employment, seniority-based wage and promotion, and enterprise unionism. ${ }^{3}$ Other notable Japanese human resource management practices include a particular quality management system, consensus decision-making, employee loyalty to the company and a lack of gender equality in the workplace. ${ }^{4}$

\section{Lifetime employment}

Traditionally, Japanese companies recruit graduates and guarantee them employment with the company for the entirety of the their career. ${ }^{5}$ There are a number of advantages to the practice of lifetime employment for both employees and the company. The company benefits as the stability of lifetime employment inspires devotion and loyalty in employees, which in turn generates improved employee performance. ${ }^{6}$ Employees are also provided with continual training in all areas of the company, making them versatile employees, with a range of skills and abilities that they can contribute to the company throughout their career. ${ }^{7}$ Lifetime employment also leads to a decreased turnover rate for the company, which means that talent is retained within the company, so the company receives a return on the human resources that it has invested in. ${ }^{8}$

2 Hofstede, 'What About Japan?'.

3 Florent Chleide. 2015. 'Japanese Management: Cultural Challenges and Coping Strategies.' Master's thesis, Louvain School of Management, Université catholique de Louvain, hdl.handle. net/2078.1/thesis:3089.

4 Chleide, 'Japanese Management'.

5 Ibid.

6 Kristina Lazaridi. 2012. 'Particularities of Japanese Management.' Journal of Business 1(2):

29-34, journal.ibsu.edu.ge/index.php/jbm/article/view/386.

7 Chleide, 'Japanese Management'.

8 Ibid. 
For employees, the primary advantage of lifetime employment is stability - employees are guaranteed to receive a pension after retirement. ${ }^{9}$ Lifetime employment also provides a strong platform for career development and steady salary increases. ${ }^{10}$

\section{Seniority-based wage and promotion system}

Hierarchy and respect for elders are key elements of Confucianism, a philosophy that strongly informs Japanese culture and religion. ${ }^{11}$ This paradigm is reflected in the seniority-based wage and promotion practice in Japanese human resource management. As employees gain knowledge and experience over time in a company, they earn new opportunities such as promotions and wage increases. ${ }^{12}$ The benefit of this system is that it guarantees career development and pay increases for employees who work in the company for a significant period of time. ${ }^{13}$ However, critics of the system argue that it 'does not allow new talent to be merged with experience and those with specialised skills cannot be promoted to the already crowded executive ranks'. ${ }^{14}$

\section{Enterprise unionism}

Enterprise unions exist in almost every Japanese company, and act as an intermediary between staff (except management) and the company (management). ${ }^{15}$ The managers meet with the union to discuss issues such as salaries, strategies and employee rights. ${ }^{16}$ These issues are approached and resolved by both parties with harmony and cooperation as the guiding cultural values. ${ }^{17}$

\footnotetext{
9 Ibid.

10 Ibid.

11 'Confucianism.' New World Encyclopedia, last modified 13 June 2013, www.newworld encyclopedia.org/entry/Confucianism.

12 Lazaridi, 'Particularities of Japanese Management'.

13 Chleide, 'Japanese Management'.

14 Ibid.

15 Lazaridi, 'Particularities of Japanese Management'.

16 Chleide, 'Japanese Management'.

17 Ibid.
} 


\section{Quality management system}

High-quality production has been a key strength of the Japanese economy. ${ }^{18}$ This may be attributed to the focus on quality management in Japanese human resource practices. In Japanese companies, quality control circles are established, consisting of six to 12 employees (ranging from upper management to ordinary workers) on a voluntary basis. ${ }^{19}$ Meetings are held once a week, where employees in the circle express ideas about how to innovate at each stage of production, in order to increase the competitiveness of the company. ${ }^{20}$ The benefit of quality control circles is that they foster mutual respect between members of the company at different ranks. ${ }^{21}$ The circles also encourage feedback and a variety of ideas from a range of members of the company, giving those who will most likely implement the ideas in the company - the workers - ownership of those ideas. This system fosters a collective sense of trust and commitment.

\section{Consensus decision-making}

There is an emphasis in Japanese culture and business on consensus decision-making; everyone in the company should collectively agree on the objectives and decisions of the company, and all conflict should be avoided. ${ }^{22}$ This consensus system is known in Japan as the 'ringi system' and is one of the most important human resource management practices in Japan. ${ }^{23}$ Decisions are made with regard to the long-term impacts of such a decision, rather than just the immediate short-term impacts. ${ }^{24}$ Japanese business decisions are made in a structured, logical and thoughtful process. ${ }^{25}$

18 Ralf Bebenroth and Toshihiro Kanai (editors). 2011. Challenges of Human Resource Management in Japan. Oxford: Routledge.

19 Chleide, 'Japanese Management'.

20 Ibid.

21 Ibid.

22 Ibid.

23 Lazaridi, 'Particularities of Japanese Management'.

24 Chleide, 'Japanese Management'.

25 Ibid. 


\section{Employee loyalty to his/her company}

Companies in Japan are built upon the philosophy that employees in the company are 'family'. ${ }^{26}$ Therefore, employees are extremely loyal to their company and place high importance on the performance of the company as a whole. ${ }^{27}$ There is an overall collective mindset in the firm (and Japanese society at large) whereby individuals are rarely singled out for praise or blame. ${ }^{28}$ Employees often work overtime without pay in order to contribute to the company's well-being: in 2013, 8.8 per cent of full-time employees worked more than 80 hours of monthly overtime. ${ }^{29}$

\section{Lack of gender equality in the workplace}

Traditionally, women are not considered equal to men in the Japanese business environment. It is difficult for female graduates to find suitable work opportunities and it has been said that 'Japanese work customs make it almost impossible for women to have both a family and a career. ${ }^{30}$

\section{A brief economic history of Japan and how this has influenced traditional Japanese human resource practices}

These traditional Japanese human resource practices emerged over a long period of time, and have been informed significantly by global historic and economic events.

During the Second World War, Japan had strict labour market regulations and there was a significant divide between blue-collar and white-collar workers with respect to both wages and working conditions. ${ }^{31}$ In the postwar

26 Markus Pudelko and Anne-Wil Harzing. 2011. 'Japanese Human Resource Management: Inspirations from Abroad and Current Trends of Change.' In Bebenroth and Kanai, Challenges of Human Resource Management in Japan, London and New York: Routledge, pp. 28-60.

27 Chleide, 'Japanese Management'.

28 Ibid.

29 Ibid., p. 30.

30 Ibid., p. 38.

31 Chiaki Moriguchi. 2014. 'Japanese-Style Human Resource Management and Its Historical Origins.' Japan Labor Review 11(3): 58-77, hdl.voced.edu.au/10707/329209. 
period, these distinctions between blue-collar and white-collar workers were broken down with the formation of employee unions - which included all employees. ${ }^{32}$ It was also during this period that the practice of lifetime employment emerged. ${ }^{33}$

In the 1950s and 1960s, the Japanese economy experienced significant growth, with GDP per capita rising at an average rate of 7 per cent per year. ${ }^{34}$ Throughout this high-growth period, the traditional Japanese human resource practices (outlined above) were developed. High growth allowed for a longterm mindset for business matters such as human resource management, which encouraged the development of practices such as emphasis on job security, career development and quality management systems.

In the 1980s, Japanese companies attracted attention globally as they were superior performers, boosted by the strong economic conditions in Japan. ${ }^{35}$ Japan's unique human resource practices were regarded as central to the success of Japanese companies, and Western businesses were eager to learn and integrate Japan's approach to human resource management. ${ }^{36}$

However, the Japanese economy suffered greatly in the 1990s due to the bursting of a speculative asset price bubble. ${ }^{37}$ This led to a decade-long recession in Japan. ${ }^{38}$ Along with this economic fall, globalisation emerged in the late 1980s and, as the world economy opened up, Japan faced competition from companies all over the world. ${ }^{39}$ Combined with declining domestic demand, cost pressures for Japanese firms were intensified and efficiency was championed more than ever. ${ }^{40}$ The recession of the 1990s was the beginning of the evolution of Japan's traditional human resource management model. ${ }^{41}$

32 Lazaridi, 'Particularities of Japanese Management'.

33 Moriguchi, 'Japanese-Style Human Resource Management'.

34 Ibid.

35 Bebenroth and Kanai, Challenges of Human Resource Management in Japan.

36 Ibid.

37 Moriguchi, 'Japanese-Style Human Resource Management'.

38 Ibid.

39 Ibid.

40 Ibid.

41 Ibid. 
Ironically, Japan's traditional human resource management model, which had been seen as central to the success of Japanese companies in the 1980s, was now seen as a cause for Japan's economic woes and a barrier to efficiency. ${ }^{42}$ In the face of global competition and intense cost pressures, the 'typical Japanese' way of managing human resources began to change.

Despite experiencing hard economic times in the 1990s, as well as the global financial crisis in 2008 and a severe earthquake in 2011, Japan remains the most developed and second largest economy in Asia. ${ }^{43}$ However, Japan does face some immediate economic challenges, primarily a rapidly ageing population. ${ }^{44}$ This is problematic as it represents a reduction in the size of the workforce as well as increasing demands on health and welfare and concurrent decreases in tax revenues.

\section{Changes to Japan's traditional human resource practices}

A tension exists in Japanese human resource management between the traditional cultural mindset, and global competitive forces and efficiency mandates. Overall, we can conclude that human resource management practices in Japan are certainly changing, primarily due to Japan's poor economic performance in recent years and the influence of globalisation on competition. However, these changes are slow and limited in some respects by Japan's traditional cultural mindset and senior employees in particular.

\section{Lifetime employment}

Lifetime employment remains relatively common in Japan, with 35 per cent of Japanese employees guaranteed employment for life in 2011. ${ }^{45}$ Although lifetime employment limits the flexibility and opportunities of one's career, the security it provides, particularly for families, remains very highly valued in Japanese culture. This is evident from the fact that lifetime employment is

\footnotetext{
42 Ibid.

43 Jodi Schneider et al. 2016. 'What's Wrong With Japan's Economy?' Bloomberg, 25 July 25: www.bloomberg.com/graphics/2016-japan-economy/.

44 Schneider, 'What's Wrong With Japan's Economy?'

45 Lazaridi, 'Particularities of Japanese Management'.
} 
an entrenched custom rather than an explicit requirement in an employment contract - it is culturally ingrained and is therefore followed without need for legal enforcement. ${ }^{46}$

However, when faced with cost pressures, lifetime employment does not lead to the best outcomes for companies or the Japanese economy; it may result in complacency, which leads to lack of incentives for innovation and efficiency of employees. ${ }^{47}$ It also may result in an inefficient allocation of human resources, whereby the right person is not employed for the right job, but this cannot be changed due to the lifetime guarantee.

It is clear that lifetime employment is not economically viable, however, due to its cultural value and tradition, it remains relatively common in Japanese companies. One reason why it remains common is that senior employees who were hired upon the expectation of lifetime employment are not willing to change this expectation..$^{48}$ It is likely that lifetime employment will gradually decline as younger generations are employed, without the promise of lifetime employment. Indeed, younger employees have expressed a preference for a more flexible career path, rather than being confined to one company. ${ }^{49}$

Overall, the practice of lifetime employment in Japan is supported by cultural traditions but is not supported by economic factors.

\section{Seniority-based wage and promotion}

Currently, 60-70 per cent of Japanese companies use a performance-based wage and promotion system. ${ }^{50}$ However, human resource decisions based upon seniority remain prevalent, and many companies have encountered problems with the transition to a performance-based system, such as lack of acceptance by senior employees. ${ }^{51}$

46 Ibid.

47 Moriguchi, 'Japanese-Style Human Resource Management'.

48 Lazaridi, 'Particularities of Japanese Management'.

49 Ibid.

50 Tomohiko Okada. 2012. 'Human Resources Management in Japan: Before and After the 1990s.' Master's thesis, MIT, hdl.handle.net/1721.1/72939.

51 Okada, 'Human Resources Management in Japan'. 
Due to the ageing of the population in Japan, the seniority-based wage system (having more senior employees receiving higher wages) increases labour costs. ${ }^{52}$ This notion supports the movement away from a seniority-based system and towards a performance-based system.

Furthermore, younger employees are resisting a system that does not reward ability and skill, but rather champions experience, which cannot be attained fast enough. Due to globalisation, opportunities to work for foreign companies with performance-based wage and promotion systems have become far more common in Japan. ${ }^{53}$ This highlights the limitations of the seniority-based system, and increasingly attracts young Japanese talent. Japanese companies are being forced to change away from the seniority-based system in order to remain competitive on the global stage. ${ }^{54}$

In summary, the seniority-based wage and promotion system is supported by Japanese culture and tradition, but it does not make economic sense.

\section{Enterprise unionism}

Enterprise unionism in Japanese companies is declining. The number of enterprise unions in Japan declined by 21 per cent between 1984-2006. ${ }^{55}$ Reasons for this may include the growing importance of the service sector in Japan, which traditionally has lower union representation. In 2016, manufacturing represents only 21 per cent of Japan's GDP, while services represent 75 per cent. ${ }^{56}$ The decline in enterprise unionism may also have been caused by the economic decline in the 1990s; during this period, enterprise unions lost their collective bargaining power as wages could not be increased due to weak demand.

52 Ibid.

53 Bebenroth and Kanai, Challenges of Human Resource Management in Japan.

54 Okada, 'Human Resources Management in Japan'.

55 John Benson and Philippe Debroux. 2004. 'The Changing Nature of Japanese Human Resource Management: The Impact of the Recession and the Asian Financial Crisis.' International Studies of Management \& Organization 34(1): 32-51, www.jstor.org/stable/40397584.

56 Stanley White. 2016. 'Japan's services sector returns to modest growth in May, PMI at 50.4.' Reuters, 2 June: www.reuters.com/article/us-japan-economy-pmi-services-idUSKCN0YP07N. 


\section{Quality management systems}

Quality control circles were championed as key to the success of Japanese companies in the 1980s. This quality management system attracted attention from Western countries that attempted to implement the system. However, in the West, 80 per cent of the sample companies that introduced quality circles abandoned them. ${ }^{57}$ It became clear that the Japanese quality management system was suited only to the collectivistic nature of Japanese workers. ${ }^{58}$ In a more individualistic society such as the USA, this quality management system seemed to identify people to blame for problems rather than identifying solutions to problems. It follows that quality management systems are not suited to individualistic cultures.

The younger generations in Japan are more individualistic than collectivistic; they have been referred to as the 'global generation', with some studies demonstrating that Japanese college students are more individualistic than even American college students. ${ }^{59}$ It is likely, therefore, that quality management systems in Japan will decline over time. However, due to the remaining influence of senior workers, a collectivist attitude prevails in Japan, and the traditional quality management system in Japan continues to be utilised effectively. ${ }^{60}$

\section{Consensus decision-making}

As outlined above, there has been an overall increase in individualistic behaviours in Japan, particularly among younger generations. Despite this, the ringi system continues to prevail in Japan, and is an ingrained mindset for Japanese society. ${ }^{61}$ This can prove challenging for international firms operating in Japan, as it is a specific and thorough decision-making process. ${ }^{62}$

57 The Economist. 2009.'Quality Circle.' The Economist, 4 November: www.economist.com/ node/14301388.

58 The Economist, 'Quality Circle'.

59 Emiko Kobayashi, Harold K. Kerbo, and Susan F. Sharp. 2010. 'Differences in Individualistic and Collectivistic Tendencies among College Students in Japan and the United States.' International Journal of Comparative Sociology 51(1-2): 59-84. doi:10.1177/0020715209343424.

60 Chleide, 'Japanese Management'.

61 Lazaridi, 'Particularities of Japanese Management'.

62 Chleide, 'Japanese Management'. 


\section{Employee loyalty to his/her company}

Loyalty continues to be valued extremely highly by managers in Japan and is fundamental in Japanese culture due to the prevailing influence of Confucian philosophy. ${ }^{63}$ However, it is likely that employee loyalty will decline in alignment with lifetime employment. It is arguable that the younger generations in Japan value flexibility and diverse career experiences over loyalty to one company. ${ }^{64}$ Furthermore, globalisation has meant that Japanese companies have internationalised and global firms have entered Japan, bringing alternative human resource management practices. ${ }^{65}$ For example, Takeda Pharmaceutical Company - the largest pharmaceutical company in Japan - now has a non-Japanese president for the first time since 1781, as well as a number of other executives who are not Japanese. ${ }^{66}$ This indicates a very significant change in Japan's human resource management practices; it signifies the globalisation - or Westernisation - of Japanese human resources and human resource practices.

\section{Lack of gender equality in the workplace}

Gender equality in the workplace in Japan is far behind the Western world. ${ }^{67}$ Female participation in the labour force is 63 per cent and 70 per cent of women stop working after they have children, compared with 30 per cent in the USA. ${ }^{68}$ This is set to change, as promised by the Japanese Prime Minister Shinzō Abe; due to Japan's shrinking workforce, female participation in the labour force is critical for the improvement of Japan's economic performance. ${ }^{69}$ This change is likely to be slow due to ingrained culture, family traditions and expectations of women.

63 'Confucianism'.

64 Lazaridi, 'Particularities of Japanese Management'.

65 Bebenroth and Kanai, Challenges of Human Resource Management in Japan.

66 Chleide, 'Japanese Management', p. 25.

67 The Economist. 2014. 'Holding Back Half the Nation; Japanese Women and Work.'

The Economist, 29 March: www.economist.com/news/briefing/21599763-womens-lowly-statusjapanese-workplace-has-barely-improved-decades-and-country.

68 The Economist, 'Holding Back Half the Nation'.

69 Ibid. 


\section{Conclusion}

The 'typically Japanese' ways in which Japanese companies have long arranged their human resource practices are certainly changing. These changes are influenced by both the traditional Japanese cultural mindset and global competitive and economic forces. These influences are often in tension, thereby limiting the rate at which Japanese human resource practices can change and evolve.

Lifetime employment is declining but it remains evident in Japanese companies. It is supported by cultural traditions but is not economically viable. Similarly, the seniority-based wage and promotion system is also declining. Indeed, this system has largely been replaced by a performance-based system. This practice is also not economically viable - especially due to the ageing population in Japan - but it is retained due to tradition and the cultural influence of senior employees in Japanese companies. Enterprise unionism has also declined throughout the difficult economic period of the 1990s in Japan. The Japanese quality management system and employee loyalty are both set to change gradually, as younger generations in Japan gain greater influence and authority, and demonstrate more individualistic characteristics in the workplace and their careers in general. Consensus decision-making and gender roles in the workplace are arguably the slowest changing human resource practices in Japan; they represent deeply ingrained cultural practices as well as human resource management practices in Japan. ${ }^{70}$ Despite this, an increase of female participation in the Japanese labour force is critical for the Japanese economy and would greatly benefit Japanese business and wider society. ${ }^{71}$

In conclusion, it is clear that the 'typically Japanese' human resource management practices are changing. These changes are slow and somewhat limited, but at the same time, they are inevitable as globalisation and younger Japanese generations exert influence in Japan.

70 Ibid.

71 Ibid. 


\section{References}

Bebenroth, Ralf, and Toshihiro Kanai (editors). 2011. Challenges of Human Resource Management in Japan. Oxford: Routledge.

Benson, John. 2008. 'The Development and Structure of Japanese Enterprise Unions.' The Asia-Pacific Journal 6(11): 1-8. apjjf.org/-JohnBenson/2938/article.html.

Benson, John, and Philippe Debroux. 2004. 'The Changing Nature of Japanese Human Resource Management: The Impact of the Recession and the Asian Financial Crisis.' International Studies of Management \& Organization 34(1): 32-51. www.jstor.org/stable/40397584.

Brasor, Philip. 2014. 'Debating the Merits of Lifetime Employment.' Japan Times, 1 November. www.japantimes.co.jp/news/2014/11/01/ national/media-national/debating-merits-lifetime-employment/\#. WCLwW3d7GgR.

Chleide, Florent. 2015. 'Japanese Management: Cultural Challenges and Coping Strategies.' Master's thesis, Louvain School of Management, Université catholique de Louvain. hdl.handle.net/2078.1/thesis:3089.

'Confucianism.' New World Encyclopedia. Last modified 13 June 2013. www.newworldencyclopedia.org/entry/Confucianism.

Diefenbach, Thomas. 2015. 'Inclusiveness and Exclusiveness of Japanese-Style Management Abroad - Some Evidence from Southeast Asia.' The South East Asian Journal of Management 9(1): 52-69. doi.org/10.21002/seam. v9i1.4375.

Hofstede, Geert. 'What About Japan?' Accessed 5 October 2016. geerthofstede.com/japan.html.

Kambayashi, Ryo and Takao Kato. 2012. 'Good Jobs, Bad Jobs, and the Great Recession: Lessons from Japan’s Lost Decade.’ Discussion Paper No. 6666, Institute for the Study of Labor, Bonn, Germany. ftp.iza.org/dp6666.pdf.

Kobayashi, Emiko, Harold K. Kerbo, and Susan F. Sharp. 2010. 'Differences in Individualistic and Collectivistic Tendencies among College Students in Japan and the United States.' International Journal of Comparative Sociology 51(1-2): 59-84. doi:10.1177/0020715209343424. 
Lazaridi, Kristina. 2012. 'Particularities of Japanese Management.' Journal of Business 1(2): 29-34. journal.ibsu.edu.ge/index.php/jbm/article/view/386.

Moriguchi, Chiaki. 2014. 'Japanese-Style Human Resource Management and Its Historical Origins.' Japan Labor Review 11(3): 58-77. hdl.voced.edu. au/10707/329209.

Okada, Tomohiko. 2012. 'Human Resources Management in Japan: Before and After the 1990s.' Master's thesis, MIT. hdl.handle.net/1721.1/72939.

Ornatowski, Gregory K. 1998. 'The End of Japanese-Style Human Resource Management?' Sloan Management Review 39(3): 73-84.

Pudelko, Markus, and Anne-Wil Harzing. 2011. 'Japanese Human Resource Management: Inspirations from Abroad and Current Trends of Change.' In Bebenroth and Kanai, Challenges of Human Resource Management in Japan, Oxford: Routledge, pp. 28-60.

Sakikawa, Takashi. 2012. Transforming Japanese Workplaces. Basingstoke, Hants.: Palgrave Macmillan. www.palgraveconnect.com/pc/doifinder/vie $\mathrm{w} / 10.1057 / 9781137268860.0001$.

Schneider, Jodi, Yue Qiu, Alyssa McDonald, Keiko Ujikane and Adrian Leung. 2016. 'What's Wrong With Japan's Economy?' Bloomberg, 25 July. www.bloomberg.com/graphics/2016-japan-economy/.

Shibata, Hiromichi and Andrew Doyle. 2006. 'International Human Resources Management of Japanese, American, and European Firms in Asia: The Roles of Headquarters and Subsidiaries.' Paper presented at the Conference, Japan Center for Economic Research, Tokyo, 1 June. www. jcer.or.jp/eng/pdf/discussion98.pdf.

The Economist. 2014. 'Holding Back Half the Nation; Japanese Women and Work.' The Economist, 29 March. www.economist.com/news/ briefing/21599763-womens-lowly-status-japanese-workplace-has-barelyimproved-decades-and-country.

The Economist. 2009. 'Quality Circle.' The Economist, 4 November. www. economist.com/node/14301388.

White, Stanley. 2016. 'Japan's services sector returns to modest growth in May, PMI at 50.4.' Reuters, 2 June. www.reuters.com/article/us-japan-economypmi-services-idUSKCN0YP07N. 
This text is taken from Merici, Volume 2, 2016, edited by Matthew Rogers, published 2017 by ANU eView, The Australian National University,

Canberra, Australia. 